\title{
Effect of nursing guideline for recently diagnosed hypertensive patients on their knowledge, self-care practice and expected clinical outcomes
}

\author{
Zeinab Hussain $\mathrm{Ali}^{1}$, Nadia Mohamed Taha ${ }^{* 2}$ \\ ${ }^{1}$ Adult Health Nursing, Faculty of Nursing, University of Helwan, Helwan, Egypt \\ ${ }^{2}$ Adult Health Nursing, Faculty of Nursing, Zagazig University, Zagazig, Egypt
}

Received: April 11, 2014

DOI: $10.5430 /$ jnep.v5n3p1
Accepted: November 9, 2014 Online Published: December 8, 2014

URL: http://dx.doi.org/10.5430/jnep.v5n3p1

\begin{abstract}
Background: Hypertension is one of the most common diseases afflicting humans worldwide, and one of the leading causes of death and disability in developing countries. The role of nursing in preventing hypertension is to create awareness, hence, its significant reduction. The aim of the study was to detect the effect of nursing guideline for recently diagnosed hypertensive patients on their knowledge,self-care practice and expected clinical outcomes.

Subjects and methods: The study was conducted in the outpatient medicine clinics in Elnasr Health Insurance and Zagazig University Hospitals, in Egypt using a controlled quasi-experimental study design with pre-post and follow-up assessments on 85 recently diagnosed hypertensive patients. The data collection tools included Demographic and Medical History Tool, knowledge assessment tool, Stress Assessment Scale, Lifestyle Habits and self-care practice Assessment Tools and the Physical Assessment and Laboratory Investigation Sheet. The researcher developed nursing guideline aimed at effecting lifestyle changes in hypertensive patients to help control their blood pressure and prevent complications. The study was achieved through four phases namely assessment, planning, implementation and evaluation. Each patient was evaluated at the assessment phase, six months after program implementation, and six months after the second evaluation.

Results: Fifteen patients dropped out. The implementation of the intervention was associated with significant improvements in all aspects of patients' knowledge at the post and follow-up tests $(p<.001)$. The total mean stress score declined from a mean $1.2 \pm 0.3$ at the pretest, to $1.1 \pm 0.4$ at posttest and $0.9 \pm 0.3$ at follow-up $(p<.001)$. There were significant improvements in blood pressure and lab findings of the patients throughout study phases $(p<.001)$. Multivariate analysis showed that the implementation of the nursing guideline was the most important independent predictor of the control of hypertension, in addition to the scores of practice of exercise, compliance and personal self care practice.

Conclusion and recommendations: Individualized custom-tailored nursing guideline can be effective in the management of recently diagnosed hypertensive patients through improving their related knowledge, self-care practices and Excepected clinical outcomes. It is recommended to apply this program as a routine in the study setting and similar ones.
\end{abstract}

Key Words: Hypertension, Nursing guideline, Self-care practices, Excepected clinical outcomes

\footnotetext{
*Correspondence: Nadia Mohamed Taha; Email: dr_nadya_mohamed@yahoo.com; Address: Adult Health Nursing, Faculty of Nursing, Zagazig University, Zagazig, Egypt.
} 


\section{Introduction}

Hypertension is one of the most common diseases afflicting humans worldwide, and one of the leading causes of death and disability in developing countries. ${ }^{[1]}$ According to a report from the World Health Organization, there was an estimated 972 million people with hypertension in the year 2000; 65\% lived in developing world with the number predicted to grow to 1.5 billion by $2025{ }^{[2]}$ It is one of the most important risk factors for cardiovascular diseases and stroke, which are the leading causes of death around the world. ${ }^{[3,4]}$

Decreasing and preventing the complications arising from hypertension is a matter of importance ${ }^{[5]}$ given its negative impact on the patients as well as country's economy and health care system. ${ }^{[6]}$ This can be achieved if it is diagnosed early and prompt and adequate management, which will lead to a lower incidence of complications. ${ }^{[7]}$ Based on the self-care model' latest revisions "Dorothy Orem's Self Care Theory", ${ }^{[8]}$ increasing patients' understanding of the disease, risk factors, complications and management have become of extreme importance, ${ }^{[9]}$ especially in developing countries with high illiteracy rates. ${ }^{[10]}$ Moreover, high rates of hypertension have been associated with low levels of awareness. ${ }^{[1]}$

The treatment of hypertension in developing countries is unaffordable for many patients. ${ }^{[12]}$ Therefore, there has been increasing emphasis on the prevention and treatment of hypertension by providing effective nursing guidelines, termed 'lifestyle modifications'. These may include improving their self care practice that include, increased physical activity, weight reduction, and reduced sodium intake, and adherence with the prescribed medication. The Dietary Approaches to stop hypertension (DASH) diet is an overall eating plan that focuses on eating twice the average daily amount of fruits, vegetables, complex carbohydrates and low-fat dairy products. ${ }^{[13]}$ Also Whelton ${ }^{[14]}$ recommended breathing exercises and stress management technique. These changes can have a great impact on maintaining health and wellbeing, as well as lowering the destructive outcomes of hypertension. ${ }^{[15]}$

The role of nursing in preventing hypertension crises and complications is to create awareness, hence, its significant reduction. ${ }^{[16]}$ The nurse must properly assess the level of self-care a patient requires so that the nurse can utilize the nursing system that best fits the patient's ability to perform self-care. ${ }^{[17]}$ In addition to the patient's role in self-care, the nurse also can be effective in taking care of them after discharge. ${ }^{[18]}$ The control of hypertension through health promotion and life style modification presents a significant challenge for a large sector of the population that is well fitting to nursing care. ${ }^{[19]}$

This can be accomplished through implementing Nursing guideline, that is a designated program provided to recently diagnosed hypertensive patients to improve their knowledge, self-care practice and clinical outcomes. It constitutes the following items, dietary modification including DASH (dietary approach to stop hypertension), weight reduction strategies, increase exercise, stress management strategies, promotion the adherence to management plane and educate patients self/home blood pressure monitoring that lead to improvement in the hypertension patients Clinical outcomes as systolic and diastolic blood pressure, triglycerides, cholesterol, RBS, FBS, PPS, creatinine, SGPT, SGOT, as well as patients clinical manifestation of hypertension as headachy, fatigue, anxiety, numbness, face and eye redness, and edema of lower extremities. ${ }^{[20]}$

\subsection{Operational definition}

Nursing guideline: It is a designated program provided to recently diagnosed hypertensive patients to improve their knowledge, self-care practice and clinical outcomes, it constitutes the following items, dietary modification including DASH (dietary approach to stop hypertension), weight reduction strategies, increase exercise, stress management strategies, promotion the adherence to management plane and educate patients self/home blood pressure monitoring. ${ }^{[20]}$

Expected clinical outcomes: It is physical sign and symptoms that patient has as systolic and diastolic blood pressure, triglycerides, cholesterol, RBS, FBS, PPS, Creatinine, SGPT, SGOT, as well as patients clinical manifestation of hypertension as headachy, fatigue, anxiety, numbness, face and eye redness, and edema of lower extremities.

Self-care practice: The practice of activities that individuals begin and do on their own behalf in maintaining life, health, and welfare. ${ }^{[21]}$

\subsection{Significance of the study}

Uncontrolled blood pressure is one of the common diseases of high prevalence in Egypt. Many of the affected people are undiagnosed, and many of the diagnosed are not under treatment or controlled. As the primary health care providers who have more opportunities to meet and be exposed to hypertensive adults and their family members, nurses are more likely to observe and provide appropriate health information and strategies, as well as encourage adaptive behavior and self-care behavior to adults patients diagnosed with hypertension. according to Global health organization the overall prevalence of raised blood pressure in adults aged 25 and over was around $40 \%$ in 2008 , in the same report Glogal health organization reported that, the number of people with uncontrolled hypertension rose from 600 million in 1980 to nearly one billion $1 \mathrm{n} 2008 .{ }^{[22]}$ Worldwide raised blood pressure is estimated to cause 7.5 million of death, about $12.8 \%$ of total of all are deaths, this account for 75 million disabilities. As well high blood pressure is risk for stork and coronary heart disease. 
Complications of raised blood pressure include heart failure, peripheral vascular disease, renal impairment, retinal hemorrhage and visual impairment. ${ }^{[22]}$ In Egypt Ibrahim, ${ }^{[23]}$ reported that, hypertension is a common health problem in Egypt, it has a high prevalence, where its rate of awareness, treatment and control are low in $60 \%$ of patients, hypertension is complicated by other cardiovascular risk factors , this adds to increased cardiovascular morbidity and mortality .According to El-nasr hospital records in 2010, the total number of cases of hypertension during the whole year were 600 , representing $75 \%$ of those complaining from cardiovascular disease in the same period?

\subsection{Aim of the study}

The aim of the study was to determine the effect of nursing guideline for recently diagnosed hypertensive patients on their knowledge, self-care practice and Expected clinical outcomes.

\subsection{Research hypotheses}

1) Patients total knowledge self-care practice means score will be significantly higher post implementation of the program.

2) Patients' Expected clinical outcomes as blood pressure and clinical investigation will be significantly within normal value post implementation of the program.

\subsection{Conceptual framework}

The theoretical framework that guided this study was Orem's model that's focuses on each individual's capacity to carry out self-care. This is defined as "the practice of activities that individuals begin and do on their own behalf in maintaining life, health, and welfare". The basic principle of the model is that individuals can take responsibility for their health and the health of others. In a common sense, individuals have the capacity to care for themselves or their relatives. ${ }^{[24]}$ Orem's model is composed of three related theories: the theory of self-care, the theory of self-care deficit, and the theory of nursing systems encompass the self-care deficit nursing theory. ${ }^{[8]}$ The model takes into consideration the four concepts of the nursing metaparadigm: person, environment, health, and nursing. ${ }^{[25]}$

\section{Subjects and methods}

\subsection{Study design and setting}

The study was conducted in the outpatient medicine clinics in El-nasr Health Insurance Hospital, at Helwan region and Zagazig University Hospital in Egypt. A controlled quasiexperimental study design with pre-post and follow-up assessments was used in this study.

Published by Sciedu Press

\subsection{Subjects}

The study involved a convenience sample of 85 recently diagnosed hypertensive patients drawn from all the patients attending the study setting during the study period, agree to participated in the study and having the inclusion criteria. The inclusion criteria were human being adult (18 years or older), newly diagnosed with hypertension (less than one year) and attending the outpatients medicine clinics. The only exclusion criterion was having other chronic diseases. However, 15 of these patients could not proceed to the following study phases mostly due to logistic reasons pertaining to time constraints and transportation.

\subsection{Tools}

The data collection tools consisted of five tools first one was demographic and medical history tool, Second tool, knowledge assessment tool, Third tools was Stress Assessment Scale, fourth tool was, Lifestyle Habits and self-care practice Assessment Tools and fifth tool was physical assessment and laboratory investigation sheet.

Tool 1: Demographic and Medical History Tool: This tool developed by the researcher and consists of two parts; first part: was used to assess patient's personal characteristics such as age, sex, marital status, educational level, income, and current job. Second part: was for medical history with emphasis on clinical pictures of hypertension such as continuous headache, fatigue, irritability, numbness, edema, etc. Face and content validity were done for the tool by five expertise in the field of nursing and medical education, and necessary modifications were done.

Tool 2: Knowledge assessment tool: developed by the researcher to assess patients knowledge regarding hypertension. It consisted of 17 multiple choice questions asking about the explanation or meaning of hypertension, its signs and symptoms, the causes and risk factors of hypotension and hypertension, the way of control and treatment of any deviation on their blood pressure, meaning and causes of hypercholesterolemia, description of diet (type-time and suitable amount) for hypertension patient, importance and time of follow-up with physician, physical activity types and rules, and hygienic care. The correct answer for any knowledge item was given a score of 1 , and the incorrect given zero with maximum score of 17 and minimum was zero. The scores of each area of knowledge were added and converted into a percent score. The area with score of $50 \%$ or higher was considered satisfactory, while the question with lower than $50 \%$ was considered unsatisfactory.

Tool 3: Stress Assessment Scale: it was adopted from Comrey ${ }^{[26]}$ to assess social and psychological factors that affect blood pressure it included 30 questions covering psychological, social and financial, work, and family stress factors. The responses to all items of this section were on a 3-point Likert scale: usually, occasionally or never, score 2,1 , and 
zero, respectively with a maximum score of 60 and minimum zero. The scores of the items of each part and category were summed-up and the total divided by the number of the items, giving a mean score. Means, standard deviations, and medians were computed.

Tool 4: Lifestyle Habits and self-care practice Assessment Tools: this tool was developed by the researcher to assess patients, life style habits and self-care practice included 68 questions on four sides which include and included nutrition, exercise, patients compliance, and self-care practice as (brush the teeth daily, wash the body daily and cleaning the internal organ). The responses to all items of this section were on a 3-point Likert scale: usually, occasionally or never, score 2, 1, and zero, respectively with a maximum score of 126 and minimum zero. The scores of the items of each part and category were summed-up and the total divided by the number of the items, giving a mean score. Means, standard deviations, and medians were computed.

Tool 5: The Physical Assessment and Laboratory Investigation Sheet: was designed to record patient's blood pressure using a standard method of measurement. ${ }^{[27]}$ It also included a section for recording the laboratory tests result as the levels of blood triglycerides, cholesterol, random blood sugar (RBS), fasting blood sugar (FBS), postprandial sugar (PPS), Creatinine, SGPT and SGOT.

\subsection{Validity and reliability of the tools}

Face and content validity were done for the tools by five expertise in the field of nursing and medical education, and necessary modifications were done. The reliability of the tool $(2,3,4$, and 5) was tested using the internal consistency method. It proved to be high with Cronbach's alpha reliability coefficients $0.9020 .922,0.833$ and $0.932 .{ }^{\text {[28] }}$

\subsection{Pilot study}

A pilot study was conducted on ten newly diagnosed hypertensive patients selected from the same study setting to check and make sure the clarity, applicability to identify any difficulties with their application, and to determine the time needed for completion of the tools. Modification of the tools was done according to pilot results to reach to the finalized form. Subjects who shared in the pilot study were not included in the main study sample.

\subsection{Procedures}

The study was achieved through four phases namely assessment, planning, implementation, and evaluation.

\subsubsection{Assessment phase}

The aim of this phase was to collect patient's data as well as to identify individualized learning needs and abilities in order to design the suitable nursing guidelines. Each recently diagnosed hypertensive patient recruited in the study sample was interviewed and physically examined upon consent using the Demographic and Medical History Tool, knowledge assessment tool, Stress Assessment Scale, Lifestyle Habits Assessment Tool and the Physical Assessment and Laboratory Investigation Sheet, Then, a blood sample was taken for lab tests.

\subsubsection{Planning phase}

Individualized nursing guidelines were developed based on the findings of the assessment, and in the light of related literature. The nursing guidelines were designed to improve patient's knowledge and self-care practice about hypertension and his/her Excepected clinical outcomes. As well during this stage, the researcher developed nursing guidelines that were aimed at effecting lifestyle changes in recently diagnosed hypertensive patients to help control their blood pressure. The intervention was designed based on review of relevant literature and custom-tailored to the patients' needs identified in the pre-test. The first part of the nursing guidelines stressed on improving patient's knowledge regarding hypertension.

It included the following items as illustrated in the patient's handout: identifying of hypertension, its causes, signs and symptoms, and effects on body system. It also enclosed the explanation of hypotension and hypertension, their causes, clinical symptoms, emergency treatment for each, and the method of avoid their occasion. The section of nutrition and exercise covered suitable diet for hypertensive patient, type of diet to be follow and which must be avoided, as well as the importance of physical activities like aerobic walking, suitable time and duration in addition to stress management manner which included muscle relaxation and imaginary technique, along with assertiveness, problem solving and time management.

The intervention also covered the types of treatment for hypertension, importance of compliance and regular follow-up with physician, and the signs and symptoms that need rapid consultation. Lastly, self care practice which emphasized on eating sensibly, reducing your salt, fat, caloric and sugar intake, exercise regularly and reducing weight, stop smoking, compliance with your prescribed medication and do daily aerobic exercise the importance and means to care for eyes, and skin, and the method of measuring blood pressure. A helpful handout was also prepared by the researcher to be given to participants.

During implementation phase: each newly diagnosed hypertensive patients in the study sample or one of their families received the designated nursing guideline according to their needs and suitable for their level of understands. The session's numbers were around three sessions per week for each patient and continued until patients or their relatives become more satisfied with the provided knowledge. Each session lasted for around 35 to 45 minutes, each patient re- 
ceived around 3-4 sessions. In each session the researchers used face to face teaching methods in order to achieved the proposed goal and allow patient to asking, discussion and reach high level of understanding. Each session divided into two parts (first part take around 25 minute concentrated on Theoretical knowledge and second part take around 10 minute for discussion, asking and answering any question). During these sessions researcher used illustrations, examples of objects, lectures, and pamphlet and power point presentations.

Regarding practical sessions it were around 3 to five sessions according to patients or their relatives' level of understanding for the given skills, each session lasted around 50 minutes during it patients and/or one of his/her family learn self care practice as haw care of his /her eyes, skin and different body area, haw to prepare the appropriate food (types and amount) in addition to the technique of measuring blood pressure by follow the following steps 1) Be seated comfortably on a chair with your elbow and forearm resting on a flat surface, 2) Attach the blood pressure monitor cuff to your upper arm, be carful that there is no differences in high between cuff and your heart, place a pillow to adjust the highest level, 3) Switch (ON) the power of the blood pressure monitor, 4) Inflate the monitor cuff manually or by pressing on bottom the blood pressure monitor, 5) Read the blood pressure from the blood pressure screen and record it and 6) Show your doctor your blood pressure in the next appointment.

The researcher also concentrated on how many blood pressure readings are recommended each time measured, patients position during measuring, factors that can cause an error of a higher blood pressure reading, the correct cuff size, the bladder width, correct time to wait in between two consecutive blood pressure readings, how to report and interpret the reading. The researcher used supplies as blood pressure apparatus during session in addition to role playing. The researcher had periodic contacts with the patients through phone or E-mail for refreshing the provided knowledge, solving any problems and answering any questions.

\subsubsection{Evaluation phase}

Three evaluations were conducted for each patient in the study; first one was at the beginning of the study as a baseline data for developing the nursing guideline according to patient's need. Second evaluation was six months following implementation of the nursing guideline to detect the effect of provided intervention on patient's level of knowledge, skills and clinical outcomes. Third evaluation was done six months after the second evaluation. The same assessment tools were used during the three evaluations.

\subsection{Administrative design and ethical considera- tions}

The study was conducted over a period of 18 months from October 2012- April 2014. After explaining the aim of the Published by Sciedu Press study an official approval was obtained from the director of the hospital. The researcher obtained Patient's informed verbal consent to participate in the study after explaining the study aim and phases. Patients were knowledgeable about their rights to refuse or withdraw, and about confidentiality of the information obtained. The study measures could not cause any risk effect on patients. Professional help was provided by the researcher to them as needed.

\subsection{Statistical analysis}

Data entry and statistical analysis were done using SPSS 16.0 statistical software package. Data were presented using descriptive statistics in the form of frequencies and percentages for qualitative variables, and means and standard deviations and medians for quantitative variables. Cronbach alpha coefficient was calculated to assess the reliability of the developed tools through their internal consistency. Quantitative continuous data were compared using the nonparametric Kruskal-Wallis test due to lack of normal distribution. Qualitative variables categorical were compared using chi-square test. Spearman rank correlation was used for assessment of the inter-relationships among quantitative variables and ranked ones. In order to identify the risk of hypertension, multiple logistic regression analysis was used. Statistical significance was at $p$-value $<.05$.

\section{Results}

The study sample included 70 hypertensive patients with more than half $(58.6 \%)$ being females, and having a mean age around fifty four years $(54.1 \pm 10.0)$. Their education was mostly illiterate (44.3), with only $21.4 \%$ having intermediate or university education. Most patients were married $(57.1 \%)$, working $(70.0 \%)$, and with insufficient income $(74.3 \%)$ (see Table 1$)$.

Table 2 illustrates marked deficiency in patients' knowledge of hypertension in all related aspects, with none of them having an overall satisfactory knowledge during the pre-program. The implementation of the program was associated with statistically significant improvements in all aspects of patients' knowledge regarding hypertension immediately at the posttest $(p<.001)$. The percentages of satisfactory knowledge reached $100 \%$ in many areas, while the lowest improvement was related to medications $(75.7 \%)$. The follow-up phase showed continued improvements in many areas as in the medications there was increased during the follow up assessment (84.3\%), while some areas demonstrated slight declines but remained significantly higher compared with the pretest $(p<.001)$. Overall, all patients $(100 \%)$ reached the level of satisfactory knowledge at the post and follow-up phases. The mean percent scores improved from baseline 1.4 to 91.3 and 91.6 at the post and follow-up phases respectively $(p<.001)$. 
Table 1: Socio-demographic and Medical Characteristics of patients in the study sample $(n=70)$

\begin{tabular}{|c|c|c|}
\hline Items & Frequency & Percent (\%) \\
\hline \multicolumn{3}{|l|}{ Age (years) } \\
\hline$\geq 18$ & 47 & 67.1 \\
\hline$<60$ & 23 & 32.9 \\
\hline Range & $30.0-76.0$ & \\
\hline Mean \pm SD & $54.1 \pm 10.0$ & \\
\hline \multicolumn{3}{|l|}{ Gender } \\
\hline Male & 29 & 41.4 \\
\hline Female & 41 & 58.6 \\
\hline \multicolumn{3}{|l|}{ Current marital status } \\
\hline Unmarried & 30 & 42.9 \\
\hline Married & 40 & 57.1 \\
\hline \multicolumn{3}{|l|}{ Educational level } \\
\hline Illiterate & 31 & 44.3 \\
\hline Read/write & 19 & 27.1 \\
\hline Basic & 5 & 7.1 \\
\hline Intermediate & 8 & 11.4 \\
\hline University & 7 & 10.0 \\
\hline \multicolumn{3}{|l|}{ Job status } \\
\hline Not working & 21 & 30.0 \\
\hline Working & 49 & 70.0 \\
\hline \multicolumn{3}{|l|}{ Income } \\
\hline Insufficient & 52 & 74.3 \\
\hline Sufficient & 18 & 25.7 \\
\hline \multicolumn{3}{|c|}{ Symptoms/signs related to hypertension } \\
\hline Headache & 57 & 81.4 \\
\hline Fatigue & 52 & 74.3 \\
\hline Anxiety & 46 & 65.7 \\
\hline Numbness & 46 & 65.7 \\
\hline Face/eye redness & 45 & 64.3 \\
\hline Edema of extremities & 38 & 54.3 \\
\hline
\end{tabular}

Table 2: Progress in hypertensive patients, knowledge throughout phases of the study

\begin{tabular}{|c|c|c|c|c|c|c|c|c|c|c|}
\hline \multirow{3}{*}{$\begin{array}{l}\text { Knowledge items } \\
\text { Satisfactory at } \\
(50 \%+)\end{array}$} & \multicolumn{6}{|c|}{ Time } & \multicolumn{2}{|l|}{ Pre-post } & \multicolumn{2}{|c|}{ Pre-FU } \\
\hline & \multicolumn{2}{|c|}{ Pre } & \multicolumn{2}{|l|}{ Post } & \multicolumn{2}{|l|}{ FU } & \multirow{2}{*}{$\chi^{2}$} & \multirow{2}{*}{$p$-value } & \multirow{2}{*}{$\chi^{2}$} & \multirow{2}{*}{$p$-value } \\
\hline & No. & $\%$ & No. & $\%$ & No. & $\%$ & & & & \\
\hline Definition & 1 & 1.4 & 69 & 98.6 & 70 & 100.0 & 132.11 & $<.001 *$ & 136.06 & $<.001 *$ \\
\hline Risk factors & 2 & 2.9 & 69 & 98.6 & 70 & 100.0 & 128.28 & $<.001^{*}$ & 132.22 & $<.001^{*}$ \\
\hline Causes & 0 & 0.0 & 70 & 100.0 & 70 & 100.0 & 140.00 & $<.001 *$ & 140.00 & $<.001^{*}$ \\
\hline Symptoms & 1 & 1.4 & 70 & 100.0 & 70 & 100.0 & 136.06 & $<.001^{*}$ & 136.06 & $<.001 *$ \\
\hline Complications & 0 & 0.0 & 70 & 100.0 & 70 & 100.0 & 140.00 & $<.001^{*}$ & 140.00 & $<.001^{*}$ \\
\hline Treatment & 2 & 2.9 & 70 & 100.0 & 70 & 100.0 & 132.00 & $<.001^{*}$ & 132.22 & $<.001^{*}$ \\
\hline Serum cholesterol & 2 & 2.9 & 69 & 98.6 & 70 & 100.0 & 128.28 & $<.001^{*}$ & 132.22 & $<.001^{*}$ \\
\hline Stimulants & 0 & 0.0 & 70 & 100.0 & 70 & 100.0 & 140.00 & $<.001^{*}$ & 140.00 & $<.001^{*}$ \\
\hline Exercise & 0 & 0.0 & 70 & 100.0 & 70 & 100.0 & 140.00 & $<.001^{*}$ & 140.00 & $<.001 *$ \\
\hline Meals & 2 & 2.9 & 68 & 97.1 & 69 & 98.6 & 124.46 & $<.001^{*}$ & 128.28 & $<.001^{*}$ \\
\hline Pickles & 0 & 0.0 & 69 & 98.6 & 68 & 97.1 & 136.06 & $<.001^{*}$ & 132.22 & $<.001^{*}$ \\
\hline Diet control & 2 & 2.9 & 69 & 98.6 & 68 & 97.1 & 128.28 & $<.001^{*}$ & 124.46 & $<.001^{*}$ \\
\hline Heredity & 1 & 1.4 & 68 & 97.1 & 64 & 91.4 & 128.28 & $<.001^{*}$ & 113.98 & $<.001^{*}$ \\
\hline Control & 2 & 2.9 & 60 & 85.7 & 58 & 82.9 & 97.39 & $<.001^{*}$ & 91.47 & $<.001^{*}$ \\
\hline Management & 3 & 4.3 & 65 & 92.9 & 58 & 82.9 & 109.92 & $<.001^{*}$ & 87.88 & $<.001^{*}$ \\
\hline Medications & 3 & 4.3 & 53 & 75.7 & 59 & 84.3 & 74.40 & $<.001^{*}$ & 90.79 & $<.001^{*}$ \\
\hline \multicolumn{11}{|l|}{ Total: } \\
\hline Satisfactory & 0 & 0.0 & 70 & 100.0 & 70 & 100.0 & \multirow{2}{*}{140.00} & \multirow{2}{*}{$<.001 *$} & \multirow{3}{*}{140.00} & \multirow{2}{*}{$<.001^{*}$} \\
\hline Unsatisfactory & 70 & 100.0 & 0 & 0.0 & 0 & 0.0 & & & & \\
\hline \multicolumn{10}{|l|}{ Score $(\max =100)$} & \\
\hline Range & \multicolumn{2}{|c|}{$0.0-17.4$} & \multicolumn{2}{|c|}{$60.9-100.0$} & \multicolumn{2}{|c|}{$56.5-100.0$} & & \multirow{3}{*}{\multicolumn{2}{|c|}{$<.001 *$}} \\
\hline Mean \pm SD & \multicolumn{2}{|c|}{$1.4 \pm 3.7$} & \multicolumn{2}{|c|}{$91.3 \pm 9.8$} & \multicolumn{2}{|c|}{$91.6 \pm 9.3$} & & & & \\
\hline Median & 0.00 & & 95.7 & & 93.5 & & \multicolumn{2}{|l|}{$H=144.88$} & & \\
\hline
\end{tabular}


Concerning stress scores shown in Table 3, illustrated that, patients in the pre-intervention phase had generally high scores, especially in the social domain $(1.4 \pm 0.5)$. All scores in all domains rerecorded statistically significant declines throughout the post and follow-up phases. The total mean stress score declined from a mean $1.2 \pm 0.3$ at the pretest, to $1.1 \pm 0.4$ at posttest and $0.9 \pm 0.3$ at follow-up $(p<.001)$. The same table indicates statistically significant improvements in all patients' habits $(p<.001)$. The highest improvements were related to hygiene and nutrition habits with their means reaching levels of 1.8 and 1.6 respectively at the posttest. On the other hand, the improvements in exercise and self-care habits were mediocre although statistically significant.

Table 3: Stress and patients, Habits and self-care practice scores among study sample throughout phases of the study

\begin{tabular}{|c|c|c|c|c|c|}
\hline & \multicolumn{3}{|l|}{ Scores } & \multirow{2}{*}{$\begin{array}{l}\text { Kruskal } \\
\text { Wallis test }\end{array}$} & \multirow{2}{*}{$p$-value } \\
\hline & Pre & Post & FU & & \\
\hline \multicolumn{6}{|c|}{ STRESS $(\max =2)$} \\
\hline \multicolumn{6}{|c|}{ Psychological } \\
\hline Range & $0.1-2.0$ & $0.0-2.0$ & $0.0-1.50$ & & \\
\hline Mean \pm SD & $1.2 \pm 0.5$ & $1.1 \pm 0.5$ & $0.9 \pm 0.4$ & 11.97 & $.003^{*}$ \\
\hline Median & 1.2 & 1.1 & 1.0 & & \\
\hline \multicolumn{6}{|l|}{ Social } \\
\hline Range & $0.2-2.0$ & $0.0-1.4$ & $0.0-1.0$ & & \\
\hline Mean \pm SD & $1.4 \pm 0.5$ & $1.3 \pm 0.5$ & $1.1 \pm 0.5$ & 19.79 & $<.001^{*}$ \\
\hline Median & 1.4 & 1.4 & 1.0 & & \\
\hline \multicolumn{6}{|l|}{ Work } \\
\hline Range & $0.3-2.0$ & $0.0-1.9$ & $0.0-1.7$ & & \\
\hline Mean \pm SD & $1.1 \pm 0.3$ & $1.1 \pm 0.4$ & $0.9 \pm 0.4$ & 9.339 & $.009 *$ \\
\hline Median & 1.0 & 1.0 & 1.0 & & \\
\hline \multicolumn{6}{|l|}{ Family } \\
\hline Range & $0.0-2.0$ & $0.0-2.0$ & $0.0-1.0$ & & \\
\hline Mean \pm SD & $1.1 \pm 0.5$ & $1.1 \pm 0.5$ & $0.8 \pm 0.5$ & 11.537 & $.003 *$ \\
\hline Median & 1.0 & 1.0 & 1.0 & & \\
\hline \multicolumn{6}{|l|}{ Total stress } \\
\hline Range & $0.4-2.0$ & $0.2-1.8$ & $0.0-1.5$ & & \\
\hline Mean \pm SD & $1.2 \pm 0.3$ & $1.1 \pm 0.4$ & $0.9 \pm 0.3$ & 21.409 & $<.001^{*}$ \\
\hline Median & 1.20 & 1.10 & 1.00 & & \\
\hline \multicolumn{6}{|c|}{ HABITS and self- care practice $(\max =2)$} \\
\hline \multicolumn{6}{|c|}{ Nutrition } \\
\hline Range & $0.2-1.80$ & $0.3-1.90$ & $0.8-2.0$ & & \\
\hline Mean \pm SD & $0.9 \pm 0.5$ & $1.3 \pm 0.4$ & $1.6 \pm 0.3$ & 71.71 & $<.001^{*}$ \\
\hline Median & 1.00 & 1.20 & 1.80 & & \\
\hline \multicolumn{6}{|l|}{ Exercise } \\
\hline Range & $0.0-1.60$ & $0.0-1.80$ & $0.0-1.80$ & & \\
\hline Mean \pm SD & $0.4 \pm 0.3$ & $0.9 \pm 0.5$ & $1.0 \pm 1.8$ & 58.12 & $<.001^{*}$ \\
\hline Median & 0.40 & 1.00 & 1.00 & & \\
\hline \multicolumn{6}{|l|}{ Compliance } \\
\hline Range & $0.0-2.0$ & $0.3-2.0$ & $1.7-2.0$ & & \\
\hline Mean \pm SD & $1.4 \pm 0.5$ & $1.6 \pm 0.5$ & $1.8 \pm 0.4$ & 40.93 & $<.001^{*}$ \\
\hline Median & 1.30 & 2.00 & 2.00 & & \\
\hline \multicolumn{6}{|l|}{ Self-care } \\
\hline Range & $0.9-1.5$ & $1.0-1.5$ & $1.0-1.4$ & & \\
\hline Mean \pm SD & $0.9 \pm 0.2$ & $1.1 \pm 0.2$ & $1.0 \pm 0.2$ & 23.63 & $<.001^{*}$ \\
\hline Median & 0.90 & 1.00 & 1.00 & & \\
\hline
\end{tabular}

Statistically significant improvements in blood pressure and lab findings of the patients throughout study phases were tabulated in Table 4 . The percentages of patients with normal blood pressure readings increased from $5.7 \%$ at the pre-program stage to $98.6 \%$ at the follow-up phase $(p<$ .001). As well most of patients had significant improvements in their lab results, with almost all of them reaching normal levels at the follow-up phase. FBS and the creati- 
nine level which was normal in almost all patients throughout the intervention phases. As well the same table indicted a significant improvement in patients, clinical manifestation as Headache, fatigue, anxiety, numbness, face and eye redness and lower limb edema $(81.4 \%, 74.3 \%, 65.7 \%$, $65.7 \%, 64.3 \%$ and $54.3 \%$ at the beginning of the study to become $0.0,1.4 \%, 1.4 \%$, and $0.0 \%$ for the rest $\%$ at the postprogram phase $(p=.0001)$.

Table 4: Lab findings and clinical manifestation of hypertension patients during the study phases

\begin{tabular}{|c|c|c|c|c|c|c|c|c|c|c|}
\hline \multirow{3}{*}{$\begin{array}{l}\text { Items within Normal } \\
\text { levels }\end{array}$} & \multicolumn{6}{|c|}{ Time } & \multicolumn{2}{|c|}{ Pre-post } & \multicolumn{2}{|l|}{ Pre-FU } \\
\hline & \multicolumn{2}{|l|}{ Pre } & \multicolumn{2}{|c|}{ post } & \multicolumn{2}{|c|}{ Follow up } & \multirow{2}{*}{$\chi^{2}$} & \multirow{2}{*}{$p$-value } & \multirow{2}{*}{$\chi^{2}$} & \multirow{2}{*}{$p$-value } \\
\hline & No & $\%$ & No & $\%$ & No & $\%$ & & & & \\
\hline Blood pressure & 4 & 5.7 & 37 & 52.9 & 69 & 98.6 & 37.56 & $<.001^{*}$ & 120.94 & $<.001^{*}$ \\
\hline Triglycerides & 3 & 4.3 & 49 & 70.0 & 66 & 94.3 & 64.74 & $<.001^{*}$ & 113.42 & $<.001^{*}$ \\
\hline Cholesterol & 2 & 2.9 & 57 & 81.4 & 69 & 98.6 & 88.62 & $<.001^{*}$ & 128.28 & $<.001 *$ \\
\hline RBS & 28 & 40.0 & 41 & 58.6 & 66 & 94.3 & 4.83 & $.03 *$ & 46.75 & $<0.001^{*}$ \\
\hline FBS & 27 & 38.6 & 36 & 51.4 & 50 & 71.4 & 2.34 & .13 & 15.27 & $<.001 *$ \\
\hline PPS & 29 & 41.4 & 45 & 64.3 & 63 & 90.0 & 7.34 & $.007^{*}$ & 36.65 & $<.001 *$ \\
\hline Creatinine & 67 & 95.7 & 68 & 97.1 & 70 & 100.0 & Fisher & 1.00 & Fisher & 0.24 \\
\hline sGPT & 21 & 30.0 & 48 & 68.6 & 66 & 94.3 & 20.83 & $<.001^{*}$ & 61.48 & $<.001^{*}$ \\
\hline sGOT & 22 & 31.4 & 52 & 74.3 & 68 & 97.1 & 25.80 & $<.001^{*}$ & 65.83 & $<.001^{*}$ \\
\hline \multicolumn{11}{|l|}{ Clinical Manifestation } \\
\hline Headache & 57 & 81.4 & 0 & 0.0 & 0 & 0.0 & 96.14 & $<.001 *$ & 96.14 & $.0001^{*}$ \\
\hline Fatigue & 52 & 74.3 & 3 & 4.3 & 1 & 1.4 & 71.9 & $<.0001 *$ & 78.97 & $<.0001^{*}$ \\
\hline Anxiety & 46 & 65.7 & 2 & 2.9 & 0 & 1.4 & 61.38 & $<.0001^{*}$ & 64.86 & $<.0001^{*}$ \\
\hline Numbness & 46 & 65.7 & 0 & 0.0 & 0 & 0.0 & 68.51 & $<.0001^{*}$ & 68.51 & $<.0001^{*}$ \\
\hline Face and eye redness & 45 & 64.3 & 0 & 0.0 & 0 & 0.0 & 66.32 & $<.0001 *$ & 66.32 & $<.0001^{*}$ \\
\hline Edema of extremities & 38 & 54.3 & 0 & 0.0 & 1 & 0.0 & 52.16 & $<.0001^{*}$ & 52.16 & $<.0001^{*}$ \\
\hline
\end{tabular}

(*) Statistically significant at $p<.05$

The study findings revealed statistically significant weak to moderate positive correlations between patient's scores of stress and their blood pressure readings and all their lab results except creatinine (see Table 5). The highest correlation was between stress and triglycerides. The table also demonstrates statistically significant weak to strong negative correlations between patients' scores of the practice of healthy habits and of knowledge and their assessment findings. Only the level of creatinine was not correlated to habits' scores, and FBS was not correlated to exercise and self-care scores. As the table shows, the strongest correlation was between patients' knowledge score and their level of cholesterol $(r=-0.673)$.

Table 5: Correlations between lab findings, patients habits, self-care and knowledge during the third assessment

\begin{tabular}{|c|c|c|c|c|c|c|}
\hline \multirow{2}{*}{ Lab findings } & \multicolumn{6}{|c|}{ Spearman rank correlation } \\
\hline & Stress & Nutrition & Exercise & Compliance & Self-care & Knowledge \\
\hline SBP & $.350 * *$ & $-.609 * *$ & $-.531 * *$ & $-.475^{* *}$ & $-.337 * *$ & $-.600 * *$ \\
\hline DBP & $.303^{* *}$ & $-.582 * *$ & $-.549 * *$ & $-.499 * *$ & $-.304 * *$ & $-.622 * *$ \\
\hline Triglycerides & $.412^{* *}$ & $-.577 * *$ & $-.472 * *$ & $-.414 * *$ & $-.325 * *$ & $-.627 * *$ \\
\hline Cholesterol & $.295^{* *}$ & $-.505^{* *}$ & $-.396 * *$ & $-.290 * *$ & $-.269 * *$ & $-.673 * *$ \\
\hline RBS & $.286^{* *}$ & $-.262 * *$ & $-.156^{*}$ & -.041 & $-.152 *$ & $-.305^{* *}$ \\
\hline FBS & $.357 * *$ & $-.193 * *$ & -.061 & $.182^{* *}$ & -.128 & $-.141^{*}$ \\
\hline PPS & $.273^{* *}$ & $-.249 * *$ & $-.147 *$ & $-.136 *$ & $-.155^{*}$ & $-.326 * *$ \\
\hline sGPT & $.361^{* *}$ & $-.419 * *$ & $-.296 * *$ & $-.283 * *$ & $-.284 * *$ & $-.419 * *$ \\
\hline sGOT & $.285^{* *}$ & $-.489 * *$ & $-.421 * *$ & $-.373 * *$ & $-.206 * *$ & $-.487 * *$ \\
\hline Creatinine & .057 & -.085 & -.031 & .016 & -.022 & $-.280 * *$ \\
\hline
\end{tabular}

$\left(^{*}\right)$ Statistically significant at $p<.05 ;(* *)$ statistically significant at $p<.01$; Patients Habits are: stress, nutrition, exercise, Compliance: and, self-care. 
In multivariate analysis (see Table 6), the implementation of the program seems to be the most important independent predictor of the control of hypertension, with an adjusted OR of 0.048. Additionally, the scores of practice of exercise and personal hygiene have independent effects on the con- trol of hypertension. Meanwhile, patient's increasing age is a risk factor for lack of control of hypertension with an OR 1.067. The model has a good fit as indicated by its r-square and Hosmer-Lemeshow tests. Also, it has a high percentage of overall classification $(89.5 \%)$.

Table 6: Logistic regression model for hypertension

\begin{tabular}{lllllll}
\hline & \multicolumn{2}{c}{ Coefficients } & \multirow{2}{*}{$\boldsymbol{P}$} & \multirow{2}{*}{ OR } & \multicolumn{2}{c}{ 95.0\% C.I. for OR } \\
\cline { 2 - 3 } & $\mathbf{B}$ & $\mathbf{S E}$ & & & Lower & Upper \\
\hline Intervention & -3.045 & .477 & .001 & .048 & .019 & .121 \\
Age & .065 & .026 & .012 & 1.067 & 1.014 & 1.122 \\
Exercise & -1.562 & .612 & .011 & .210 & .063 & .695 \\
Personal self care & -1.017 & .577 & .078 & .362 & .117 & 1.121 \\
Constant & 5.296 & 1.603 & .001 & 199.439 & & \\
\hline
\end{tabular}

Note. Hosmer and Lemeshow Test: $p=.533$; Model chi-square: 174.291 ( $p<.001)$; Nagelkerke $\mathrm{R}^{2}$ : 0.752; Overall classification percentage: 89.5\%; Variables entered and excluded: sex, education, scores of stress; Nutrition, self-care, knowledge.

\section{Discussion}

Hypertension is the most widespread non-communicable disease causing significant morbidity/mortality through cardiovascular, cerebro-vascular, and renal complications. The present study was set to test the hypotheses that a nursing guidelines that, based on lifestyle modification would lead to significant improvements in hypertensive patients' knowledge, self-care practice and habits, with subsequent positive impact on their Excepected clinical outcomes as blood pressure and related lab findings. The study results demonstrated significant improvements in all these parameters, which lead to acceptance of the hypotheses.

According to the current study finding, there was major deficiency in hypertensive patients' knowledge. These were evident in all areas of related knowledge and indicate that the care providers do not give due importance to health education for these patients despite the known importance of the role of health education. In this regard, Surya ${ }^{[29]}$ stressed that lifestyle modification is recommended as initial therapy in stage 1 hypertension and it can reduce the incidence of hypertension and lower end-organ damage. In line with this present study finding, Ibrahim ${ }^{[30]}$ reported that hypertensive patients in Egypt had lack of knowledge concerning the basic parameters of blood pressure monitoring and controlling complications as well as of information about the disease nature, causes, sign and symptoms, and management, which may lead to increase the incidence of complications as a result of low compliance, as well as. Similar low levels of knowledge were reported in studies from Nigeria, ${ }^{[31]}$ Swe$\operatorname{den}^{[32]}$ and USA. ${ }^{[33]}$

The implementation of the nursing guideline program in the present study led to significant improvements in patients' knowledge at the posttest and this was retained at the followup. This improvement is certainly attributed to the content and process of the intervention, which was individu- alized according to patient's needs. In congruence with this, Viera $^{[33]}$ clarified that the identification of gaps in people's knowledge about hypertension can aid in the development of messages to enhance that knowledge. The study findings also demonstrated significant negative correlations between knowledge scores and blood pressure levels and most of the lab findings, which indicate the positive impact of improving knowledge on hypertension and its related parameters. In agreement with this, a study in India found that improving patient's knowledge regarding nursing guideline program for reducing blood pressure was effective in young pre-hypertensive and hypertensive adults. ${ }^{[34]}$

The current study identified pre-program high stress scores among patients, particularly the social stress, and on the contrary low scores of healthy habits and self-care practice, especially regarding exercise. These findings reflect their deficient related knowledge, and would have a negative impact on their control of hypertension. In fact, the present study showed that stress scores were positively correlated to blood pressure levels and lab results indicating the risk of stress. In line with this, $\operatorname{Park}^{[35]}$ found a significant association between lack of physical exercise and deficient control of hypertension especially among young adults. Moreover, stress can cause blood pressure to spike, ${ }^{[36,37]}$ and chronic stress exposes body to unhealthy, persistently elevated levels of stress hormones like adrenaline and cortisol, with changes in the mode blood clots, which increases the risk of heart attack and stroke. ${ }^{[38]}$

At the post-program and follow-up phases, patients' mean stress scores declined significantly, while their scores of healthy habits significantly improved, especially regarding hygiene and nutrition habits. These changes indicate the success of the intervention, which is positively reflected on blood pressure control. This was confirmed by the findings of negative correlations between patients' scores of the prac- 
tice of self-care practice and healthy habits and their blood pressure and lab findings, indicating the positive impact of these lifestyle changes. Furthermore, in multivariate analysis, the scores of exercise and personal hygiene were independent negative predictors of the risk of hypertension, which adds to the importance of exercise. In equivalence with this, Hema ${ }^{[39]}$ showed that physical exercise is the most effective choice of nursing guideline program interventions. Thus, Fagard and Cornelissen ${ }^{[40]}$ emphasized that exercise is a cornerstone therapy for the prevention, treatment and control of hypertension.

Nonetheless, the current study revealed that the improvements in exercise habits were minimal although statistically significant. This might be explained by the difficulty of inducing a behavioral change that might need daily compliance, in addition to the lack of time and facilities to practice exercise. In agreement with this, Anshel and Kang ${ }^{[41]}$ highlighted that the literature shows that interventions have met moderate success in permanently changing exercise behavior. Moreover, increased physical activity or fitness associated with the interventions diminished with time after the intervention ended.

In multivariate analysis, the nursing guideline program was identified as the most important negative predictor of hypertension, i.e. a positive predictor on its control. As its OR indicates, it reduces the risk by majority of the patients $95 \%$. This is a further confirmation of the success of the study intervention regardless other personal factors. This success can be contributed to two reasons. First, it was individualized and tailored to each patient's needs. Second, it emphasized the practical part associated with self-care, which make patients feel more independent in the care of his/her own condition.

In agreement with the foregoing finding, Drevenhorn ${ }^{[32]}$ in Sweden studied the effects of using a structured nursing guideline program in hypertension care. The degree of exercise increased, which may be a result of increased knowledge about what the patients could do themselves to affect blood pressure and health and a reduction in systolic blood pressure was indeed correlated to increased exercise. On the same line, $\mathrm{Zafar}^{[42]}$ documented that a key goal in controlling blood pressure and its complications is to guide patients

\section{References}

[1] Reddy K.S., Naik N., and Prabhakaran D. Hypertension in the developing world: a consequence of progress. Curr Cardiol Rep. 2006; 8: 399-404. http://dx.doi.org/10.1007/s11886-006-0096-9

[2] WHO. Global health risks. Mortality and burden of disease attributable to selected major risks. 2009.

[3] Chockalingam A., Campbell N.R., and Fodor J.G. Worldwide epi- to change their lifestyles by improving their awareness regarding hypertension-related issues as risk factors and complications that is the ultimate goal of all health interventions. Moreover, Kelley ${ }^{[43]}$ showed that improving patients, selfcare practice and habits as aerobic exercise and a prudent diet would result in a $15 \%$ reduction in the rate of coronary heart disease.

The ultimate goal of the current study was to attain better control of hypertension, with reduction of its complications as revealed by hypertension sign and symptoms and lab tests. The findings revealed significant improvements in blood pressure and lab findings throughout study phases, with almost all patients being controlled by the end of the intervention. Thus the main study hypothesis was achieved. The findings are in agreement with those of a quasi experimental pretest and pos-test study without control group in Mexico. ${ }^{[44]}$ The program showed beneficial effects on blood pressure and hypertension sign and symptoms, as an activity in the nursing educator role. However, the merit of the present study was the inclusion of a follow-up assessment which serves confirming the maintenance of the lifestyle changes and associated gains, and this is not done in many studies. In fact, a meta-analysis of 127 studies and 14 dissertations, Matchar ${ }^{[45]}$ reported that only about $20 \%$ of the studies included a follow-up to the intervention.

\section{Conclusion and recommendations}

The study findings concluded that individualized customtailored nursing guideline can be effective in the management of recently diagnosed hypertensive patients through improving their related knowledge and self-care practices. The positive effect of the program is long lasting.

Based on these findings it is recommended to apply this intervention as a routine care in the study setting and similar ones. All the nurses in the outpatient clinics should be trained in delivering the intervention to their patients. The illustrative booklet should be distributed to hypo and hypertension patients.

\section{Conflicts of Interest Disclosure}

The author declares that there is no conflict of interest statement. demic of hypertension. Can J Cardiol. 2006; 22: 553-5. http: //dx.doi.org/10.1016/S0828-282X (06) 70275-6

[4] Cunha J.P., and Marks J.W. High blood pressure (hypertension). 2011.

[5] Kearney P.M., Whelton M., Reynolds K., Whelton P.K., and He J. Worldwide prevalence of hypertension: a systematic review. J Hypertens. 2004; 22: 11-9. http://dx.doi.org/10.1097/00004 872-200401000-00003

[6] Druss B.G., Marcus S.C., Olfson M., Tanielian T., Elinson L., Pin- 
cus H.A. Comparing the national economic burden of five chronic conditions. Health Aff (Millwood). 2001; 20: 233-41. http://dx .doi.org/10.1377/hlthaff.20.6.233

[7] Staessen J.A., Wang J.G., and Thijs L. Cardiovascular protection and blood pressure reduction: a meta-analysis. Lancet. 2001; 358: 1305-15. http://dx.doi.org/10.1016/S0140-6736(01 ) $06411-X$

[8] Dorothy Orem's Self Care Theory. Nursing theory. http://currentnursing.com/nursing_theory/self_c are_deficit_theory.htmlupdatedonFebruary4, 2012

[9] Mosca L., Jones W.K., King K.B., Ouyang P., Redberg R.F., Hill M.N. Awareness, perception, and knowledge of heart disease risk and prevention among women in the United States. Arch Fam Med. 2000; 9: 506-15. http://dx.doi.org/10.1001/archfami.9. 6.506

[10] Maher D., Smeeth L., and Sekajugo J. Health transition in Africa: practical policy proposals for primary care. 2011.

[11] Addo J., Amoah A.G., and Koram K.A. The changing patterns of hypertension in Ghana: a study of four rural communities in the Ghana district. 2006.

[12] ProCor. C. Charting the history of hypertension in Ghana. Pobee J.O.M. An interview by Dr. Collins Kokuro. 2009.

[13] Bellows L., and Moore R. Diet and Hypertension, Updated Thursday. 2013.

[14] Whelton S.P., Chin A., Xin X., and He J. Effect of aerobic exercise on blood pressure: a meta-analysis of randomized, controlled trials. Ann Intern Med. 2002; 136: 493-503. http://dx.doi.org/10. 7326/0003-4819-136-7-200204020-00006

[15] Pratsani S. "The Relationship of Basic Conditioning Factors, Knowledge, Self-care Agency, Self-care Behavior, and Urinary Sodium Excretion of Hypertensive Older Adults: Testing Orem's Self-Care Theory. " PhD diss., University of Tennessee. 2012.

[16] Oliviera A.S., Chen R.S., McCarthy B.D., Davis C.C., Hill M.N. Hypertension Knowledge, Awareness, and Attitudes in a Hypertensive Population. 2005

[17] Masters K. Nursing Theories: A Framework for Professional Practice. Sudbury, MA: Jones and Bartlett Learning, LLC. 2011.

[18] Ibrahim A. Theoretical Nursing Development \& Progress. Tehran: Salami-Jameh Negar. Edition 5, No. 5, Lippincott Williams \& Wilkins. 2009

[19] Hong W-H.S. Evidence-based Nursing Practice for Health Promotion in Adults with Hypertension: A Literature Review. Asian Nursing Research; December. 2010; 4(4): 227-245. http://dx.doi.o $\mathrm{rg} / 10.1016 / \mathrm{S} 1976-1317$ (11)60007-8

[20] National quality measure clearinghouse. Nursing Management Of Hypertension, Association Of Ontario (RNAO). 2009.

[21] Segen's Medical Dictionary. Farlex, Inc. All rights reserved, http://medical-ictionary.thefreedictionary.com/self-care

[22] WHO. raised blood pressure. Global health organization. 2008.

[23] Ibrahim M. Epidemiology of Hypertension in Egypt. Saudi J Kidney Dis Transpl. 1999; 10: 352-6. PMid:18212445

[24] King I. A theory for nursing: Systems, concepts, process. New York, NY: John Wiley and sons. 1981

[25] Kozier B., Erb G., Berman A., Snyder S.J., Lake H. and Kozier E. Fundamentals of Nursing. Concepts, Process, and Practice. Pearson international Edition. 8th edition. New Jersey Company. John Wiley \& Sons. 2008

[26] Comrey AL. Factor-analytic methods of scale development in personality and clinical psychology. J Consul Clin Psychol. 1988; 56: 754-61. http://dx.doi.org/10.1037/0022-006X.56.5.754

[27] Pickering T.G., Appel L.J., Graves J., Jones D., and Sheps S.G. Recommendations for blood pressure measurements in humans and experimental animals. Hypertension. 2005; 45: 142. PMid:15611362 http://dx.doi.org/10.1161/01.HYP. $0000150859.47929 .8 \mathrm{e}$

[28] Talbot L A. Principles and Practice of Nursing Research, Mosby. 1995.

[29] Surya P, Bhatt T.K., Luqman A, and Randeep G. Nonpharmacological management of hypertension, Department of Internal Medicine, All India Institute of Medical Sciences, Ansari Nagar, New Delhi, India. 2007; 61(11): 616-624.

Published by Sciedu Press
[30] Ibrahim M. problem of hypertension in Egypt. The Egyptian heart journal. 2013; 65(3): 233-234. http://dx.doi.org/10.1016/j .ehj.2013.03.005

[31] Familoni B.O., Ogun S.A., and Aina A.O. Knowledge and awareness of hypertension among patients with systemic hypertension. $\mathrm{J}$ Natl Med Assoc. 2004; 96: 620-24. PMid:15160976

[32] Drevenhorn E. Outcomes following a programme for lifestyle changes with people with Hypertension. Journal of Nursing and Healthcare of Chronic Illness. 2007; 16(7b): 144-151.

[33] Viera A.J., Cohen L.W., Mitchell C.M., and Sloane P.D. High blood pressure knowledge among primary care patients with known hypertension:. J Am Board Fam Med. 2008; 21(4): 3008. PMid:18612056 http://dx.doi.org/10.3122/jabfm. 200 8.04.070254

[34] Whelton P.K., He J., and Appel L.J. Primary prevention of hypertension clinical and public health advisory from the National High Blood Pressure Education Program. JAMA. 2002; 288: 1882-8. http://dx.doi.org/10.1001/jama.288.15.1882

[35] Park S., Rink L.D., and Wallace J.P. Accumulation of physical activity leads to a greater blood pressure reduction than a single continuous session, in prehypertension. J Hypertens. 2006; 24: 176170. PMid:16915025 http://dx.doi.org/10.1097/01.hjh.00 00242400.37967 .54

[36] Mancia G. Long-term risk of sustained hypertension in whitecoat or masked hypertension. Hypertension. 2009; 54: 226. PMid:19564548 http://dx.doi.org/10.1161/HYPERTENSIO NAHA . 109. 129882

[37] Hamer M. Psychophysiological risk markers of cardiovascular disease. Neuroscience and Biobehavioral Reviews. 2010; 35: 76. PMid:19909773 http://dx.doi.org/10.1016/j.neubior ev.2009.11.004

[38] Grossman E. Section II: Diabetes Complications and HypertensionNovel Insights into Pathophysiology and Management: Does Increased Oxidative Stress Cause Hypertension? Diabetes Care. 2008; 31: S185-S189. PMid:18227483 http://dx.doi.org/10. 2337 /dc08-s246

[39] Hema Subramanian M., Bala Soudarssanane R, Jayalakshmy D, Thiruselvakumar D, Navasakthi, Ajit Sahai, and Saptharishi LG. Non-pharmacological Interventions in Hypertension: A Community-based Cross-over Randomized Controlled Trial, Department of Preventive and Social Medicine, Jawaharlal Institute of Postgraduate Medical Education and Research. 2011; 36(3).

[40] Fagard R.H., and Cornelissen V.A. Effect of exercise on blood pressure Fagard R.H., and Cornelissen V.A. Effect of exercise on blood pressure control in hypertensive patients. Eur J Cardiovasc. 2007; 14(1): 12-7.

[41] Anshel M.H., and Kang M. Effectiveness of Motivational Interviewing on Changes in Fitness, Blood Lipids, and Exercise Adherence of Police Officers: An Outcome-Based Action Study. J Correct Health Care. 2008; 14: 48. http://dx.doi.org/10.1177/107834580 7308846

[42] Zafar S.N., Gowani S.A., and Irani F. A. Awareness of the risk factors, presenting features and complications of hypertension amongst hypertensives and normotensives, Aga Khan University. 2008.

[43] Kelley G.A., Kelley K.S., Roberts S., and Haskell W. Efficacy of aerobic exercise and a prudent diet for improving selected lipids and lipoproteins in adults: a meta-analysis of randomized controlled trials. BMC Medicine. 2011; 9: 74. PMid:21676220 http: //dx.doi.org/10.1186/1741-7015-9-74

[44] Reza C.G., Sanchez P.B.M., Pilar M.M., and Castro M.E.M. Ejercicio físico con ritmo: intervención de enfermería para el control de la hipertensión arterial en un municipio del estado de México. Esc. Anna Nery. 2013.

[45] Matchar D.B., Patwardhan M.B., and Samsa G.P. Improving adherence with clinical guidelines. In H. B. Bosworth, E. Z. Oddone, \& M. Weinberger (Eds.), Patient treatment adherence: Concepts, interventions, and measurement. Mahwah, NJ: Lawrence Erlbaum. 2006; 475- 89. 